\title{
Therapeutics
}

\section{Rofecoxib or naproxen do not slow progression of mild to moderate Alzheimer's disease}

\author{
Aisen P, Schafer K, Grundman M, et al. Effects of rofecoxib or naproxen vs placebo on Alzheimer disease progression: \\ a randomized controlled trial.JAMA 2003;289:2819-2826.
}

\section{QUESTION: Do rofecoxib or naproxen slow cognitive decline in people with mild to moderate Alzheimer's disease?}

\section{Design}

Randomised double blind placebo controlled trial.

\section{Setting}

40 ambulatory treatment centres associated with the Alzheimer's Disease Cooperative Study, USA; December 1999 to November 2000 .

\section{Participants}

351 people, aged 51 years or more, with mild to moderate Alzheimer's disease (mini-mental state examination score 13 to 26). Concomitant use of cholinesterase inhibitors, oestrogen, aspirin and vitamin $\mathrm{E}$ were permitted. Those allergic to rofecoxib or naproxen, or with peptic ulcer, liver or kidney disease, poorly controlled hypertension, heart failure or bleeding disorder, or who were being treated with other antiinflammatory drugs or treatments for Alzheimer's disease (other than those listed above), were excluded.

Source of funding:

This work was funded by the National Institute on Aging, from the General Clinical Research Center Program of the National Center for Research Resources, National Institutes of Health.

For correspondence: $P$ Aisen. Department of Neurology, Georgetown University Medical Center, Bldg D, Suite 207, 4000 Reservoir Rd, NW, Washington, DC 20057. E-mail: psa@georgetoom.edu

\section{Intervention}

Rofecoxib $25 \mathrm{mg}$ daily or naproxen $220 \mathrm{mg}$ twice daily or placebo for 1 year.

\section{Main outcome measures}

The primary outcome was the change in the cognitive subscale of the Alzheimer's Disease Assessment Scale (ADAS-Cog) after 1 year. The ADAS-Cog is scored from 0 (no impairment) to 70 (profound impairment). Secondary outcomes included activities of daily living, quality of life, time to institutionalisation or death.

\section{Main results}

At 1 year, there were no significant differences in either cognitive decline (see table) or any of the secondary outcome measures among groups.

Table Intent-to-treat analysis of mean ADAS-Cog scores

\begin{tabular}{lccc} 
Mean ADAS-Cog scores & $\begin{array}{l}\text { Placebo } \\
(\mathbf{n}=111)\end{array}$ & $\begin{array}{l}\text { Rofecoxib } \\
(\mathbf{n}=122)\end{array}$ & $\begin{array}{l}\text { Naproxen } \\
(\mathbf{n}=118)\end{array}$ \\
Baseline & 24.2 & 23.9 & 24.4 \\
\hline 1 year follow up & 29.9 & 31.0 & 30.2 \\
\hline Change from baseline & 5.7 & 7.6 & 5.8 \\
\hline P value for change compared with placebo & & 0.09 & 0.96 \\
\hline
\end{tabular}

\section{Conclusions}

The results show that neither naproxen nor rofecoxib slow cognitive decline in people with mild to moderate Alzheimer's disease.

\section{COMMENTARY}

The role of estrogens and NSAIDs in the putative prevention or treatment of Alzheimer's disease remains to be clarified. There is evidence that non-steroidal antiinflammatory agents (NSAIDs) might affect both the metabolism of amyloid beta protein, ${ }^{1}$ and the incidence of Alzheimer's disease. ${ }^{2}$ This paper describes an RCT in which participants with probable Alzheimer's disease were randomised to a Cox-2 inhibitor (rofecoxib), a non-selective NSAID (naproxen), or placebo. The aim of the study was to determine whether NSAIDs slow disease progression. The primary outcome was performance on the Alzheimer's Disease Assessment Scale, cognitive sub-score. Secondary outcomes included measures of activities of daily living and quality of life. The treatment period was one year.

In essence, the result of this trial was negative. Neither the primary nor secondary outcomes demonstrated any significant effect from NSAIDs. Since the study was probably powered adequately, and data were analysed on an intention to treat basis, it provides no support for the efficacy of these drugs in the treatment of Alzheimer's disease over a 1 year period. It is possible that a longer period of treatment might be needed ${ }^{3}$ but difficult to see that this is likely. Given the epidemiological indication that NSAIDs might reduce the incidence of Alzheimer's disease, research effort would, as the authors point out, now be better directed at a prevention study. For the time being there is no reason to change current clinical practice and begin to prescribe NSAIDs for treatment of Alzheimer's disease. NSAIDs have significant adverse effects on the gastrointestinal and cardiovascular systems, especially in older people (the people who get Alzheimer's disease), so that very clear evidence is needed before they are prescribed. These authors deserve credit for adding a little clarity to the debate.

Robin Jacoby, DM FRCP FRCPsych Professor of Old Age Psychiatry University of Oxford Oxford, $U K$

1 Akiyama H, Barger S, Barnum S et al. Inflammation and Alzheimer's disease. Neurobiol Aging 2000; 21: 383-421.

Etminan M, Gill S, Samii A. Effect of non-steroidal anti-inflammatory drugs on risk of Alzheimer's disease: systematic review and meta-analysis of observational studies.

Stewart WF, Kawas C, Corrada M, Metter EJ. Risk of Alzheimer's disease and duration of NSAID use. Neurology 1997; 48: 626-32 